\title{
EL CUERPO AUSENTE (Sor Juana y el retrato de Lisarda)
}

En una de sus composiciones más llenas de curiosidad y, en cierto modo, más reveladoras de su poética -entendida como un quehacer y a la vez como la concepción de ese quehacer-, Sor Juana se queja de la penuria de los poetas de su tiempo, obligados a volver una y otra vez sobre gastadas metáforas y a deteriorar el valor expresivo de los elementos del mundo natural por su mecánica utilización como términos comparativos. Me refiero a los ovillejos en que pinta el retrato de Lisarda y que en la edición de Méndez Plancarte lleva el número 214¹. En dicha composición, la poeta añora, o declara añorar, aquella edad en que las estrellas "aún no estaban cansadas de ser ojos" y en que "era el Sol nuevo, flamante / y andaba tan valido lo brillante / que el decir que el cabello era un tesoro, / valía otro tanto oro". ¿Es que debemos ver en Sor Juana a una precursora de la actitud de los poetas románticos que exaltaron la originalidad como un valor decisivo? ¿ $\mathrm{O}$ se trata, una vez más, de la muestra de uno de esos ingeniosos ejercicios siempre tan caros a los poetas manieristas? No olvidemos

1 Tomás Navarro Tomás (Métrica española: reseña histórica y descriptiva, University of Syracuse, Syracuse, 1956) define el ovillejo como una estrofa "de diez versos en que figuran tres pareados, cada uno formado por un octosílabo y un quebrado a manera de eco, a los cuales sigue una redondilla que continúa la rima del último pareado y termina reuniendo los tres breves quebrados en el verso final". Méndez Plancarte se inclina por esta definición (citando al propio Rengifo) y ejemplifica este tipo de composición recurriendo al mismo ejemplo de Tomás Navarro, esto es, la estrofa de Cervantes que comienza: “¿Quién menoscaba mis bienes? / desdenes...”. Sin embargo, Méndez Plancarte (Obras completas de Sor Juana Inés de la Cruz, F.C.E., México, 1986, t. 1, p. 558, n. 214) cita también otras fuentes (como Luzán y el propio Dicc. Aut.) que llaman ovillejos a una composición que combina endecasílabos y heptasílabos en versos pareados, como la realizada por Sor Juana y su antecesor Jacinto Polo de Medina. El uso de los versos pareados era frecuente en la poesía del siglo XvII. 
que estos poetas vieron en la poesía un continuo desafío a su capacidad de agudeza verbal y que no se propusieron tanto crear nuevos términos cuanto reelaborar los ya creados. Por lo pronto, los citados lamentos de Sor Juana vienen incluidos en una composición en la que comienza declarando que se propone hacer un retrato en "estilo llano", es decir que se propone emprender un ejercicio ya codificado, ejercicio en el que imitará -y desde luego intentará sobrepasar- el "jocoso numen" de Jacinto Polo.

Aunque hoy sea un autor poco conocido más allá del círculo de los estudiosos de la poesía española de los Siglos de Oro, Salvador Jacinto Polo de Medina, "poeta de vivísimo ingenio, incansable y feliz sobremanera en apodos y calificaciones" ${ }^{2}$, cuya existencia se situó entre la de Góngora y la de Sor Juana (16071657), gozó en su tiempo de justa celebridad porque supo expresar el impulso paródico y la tentación satírica que acompaña, como una especie de bajo continuo, a las desmesuras del barroco y sobre todo a las acrobacias del manierismo ${ }^{3}$. En un universo de exaltadas metáforas en el que el oro más fulgente y hasta el más ardiente sol palidecían frente a una hebra de cabello femenino, y donde tales énfasis no eran resultado de un furor dionisíaco sino, por el contrario, de un disciplinado trabajo verbal, el poeta no podía ignorar que sus comparaciones, conscientemente excesivas, llevaban lo grandioso al borde de lo insensato. Tan elaboradas metáforas eran una celebración de la palabra y a la vez una especie de guiño hecho al lector. Si Jacinto Polo reunió hacia 1637, en El buen humor de las musas, la mayor parte de aquellas composiciones con las que se burló de las pompas culteranas, eso no lo hacía

2 Adolfo de Castro, BaE, t. 2, p. lxiii.

${ }^{3}$ Con el fin de evitar posibles confusiones, tal vez sea necesario aclarar que en la distinción entre Barroco y Manierismo, así como en la definición de este último estilo, he seguido los clásicos estudios de ArNOLd HAuser contenidos en Literatura y manierismo (Guadarrama, Madrid, 1969; véase particularmente "El concepto de Manierismo"). En la segunda parte de mi libro (pp. 93 ss.), Los extremos del lenguaje en la poesía tradicional española (UNAM, México, 1981), he expuesto las dificultades a que nos enfrenta, pero también la conveniencia de adoptar los criterios de Hauser, criterios que, desde entonces, he seguido en mis trabajos. En la p. 94 del citado libro, he tratado de sintetizar la diferencia entre un estilo y otro de la siguiente manera: "[Hauser distingue] una dirección hacia un estilo áulico, rigurosamente selectivo, internacionalista e intelectualista (una «experiencia de cultura y no de vida») a la que ha llamado Manierismo, y otra más cargada de una vitalidad sensualista, de valores sentimentales y morales ligados a la nacionalidad, y por eso mismo más próximos a lo popular, a la que ha llamado Barroco”. En este sentido, el presente artículo puede leerse como un análisis del Manierismo. 
menos culterano, o menos gongorista, sino más bien confirmaba que se había formado en tal escuela: al cabo el propio Góngora -como Sor Juana y en general los poetas de la época- ensayaron la vena jocosa y hasta grosera para ridiculizar lo que en otras composiciones habían tratado con tan afectada seriedad. También confirmaba que, en la incesante búsqueda de ecuaciones comparativas, el interés de los poetas no estaba del lado del término comparado - es decir, de lo real-sino del comparante, la palabra fastuosa y distanciada.

Como es notorio, uno de los temas preferidos por esta tradición poética fue el retrato femenino, tema que era capaz de reunir -más felizmente que otros- los motivos semánticos que provenían tanto de la poesía latina como de la del amor cortés, con los motivos retóricos inaugurados o consagrados por Petrarca en su celebración de la belleza de Laura 4 . Fue Petrarca el que dio forma al canon de la belleza femenina y también al repertorio de materias suntuarias que podían servir como términos comparativos, del mismo modo que consagró el orden que debía seguir la descripción, es decir la mirada, en su recorrido del cuerpo idealizado. Este canon -reproducido por la poesía italiana y la poesía española del Renacimiento, y exacerbado por la poesía del Barroco-, para el cual la belleza y el amor alcanzan su expresión más pura en el rostro femenino, prescribe las características aparienciales, los símiles y las formas de la contemplación de dicho rostro. Así, las características son, en términos generales, las siguientes: cabello rubio, ojos brillantes, piel blanca, mejillas arreboladas, labios rojos, dientes pequeños, regulares y blancos, cuello esbelto; por su parte los símiles serían extraídos del mundo celeste, del reino mineral y del triunfo de la primavera: el sol y el oro para los cabellos, las estrellas para los ojos, la nieve, el cristal o la azucena para la piel, la rosa para las mejillas, el clavel o el coral para los labios, las perlas para los dientes, el tallo de la flor para el cuello; la contemplación de los atributos debía trazar un movimiento de arriba hacia abajo (más adelante el retrato incluiría también el cuerpo:

${ }^{4}$ Cf. I Sonetti del Canzionere, ed. A. Pentimalli, Bosch, Barcelona, 1981. A lo largo de su estudio Poesía española (Gredos, Madrid, 1966), DÁmaso Alonso ha analizado la presencia del petrarquismo en la poesía española de los Siglos de Oro. Véase esp. "Monstruosidad y belleza en el Polifemo de Góngora", el "Tema de Galatea” (pp. 370 ss.). También del mismo autor, véase el cap. "Un aspecto del petrarquismo", en D. Alonso y Carlos Bousoño, Seis calas en la expresión literaria española, Gredos, Madrid, 1970, y los caps. "La simetría bilateral" y "El soneto de Petrarca a Góngora” de Estudios y ensayos gongorinos, Gredos, Madrid, 1955. 
los hombros, los brazos y las manos, la cintura, las piernas y los pies, pasando por una apreciación global del "talle") y en ese movimiento debía recoger impresiones visuales -que corresponden a la imagen de la belleza- a las que podían agregárseles impresiones térmicas encargadas de sugerir los efectos del amor: ardor, frialdad, etcétera.

De raíz neoplatónica, esta maquinaria puesta en marcha para la producción del retrato perseguía la imagen de una perfección y en esa medida se alejaba del mundo de los hombres. Reducido a un deslumbrante, primero, y después monótono repertorio de materias ornamentales -o de énfasis retóricos- el cuerpo perdió interés como materia viva y hasta podría decirse que desapareció de la vista del poeta. El interés no estaba centrado en el "original" -es decir, en el cuerpo- sino en la "copia”, pero ésta no era una copia del "original" sino la reproducción de un modelo. En rigor, podría decirse que el original era el modelo: una especie de ritual retórico. Cuando, más tarde, ya ni el modelo interese por sí mismo sino como motivo para los ejercicios del ingenio verbal, cuando los ojos, cansados de ser estrellas, se conviertan en "ojos" pero ahora no en los ojos que lucen en el rostro de la bella -la bella Galatea, en el retrato que le dedica Góngora- sino en los "lucientes ojos" que constelan el plumaje del pavo real, ya no se sabrá demasiado bien cuál es el original y cuál la copia, como tampoco se sabrá si se está ante el retrato o ante una sutil parodia del retrato. Movida de aquí para allá por los poetas manieristas, la máquina de producir retratos hizo del cuerpo una entidad indecible -además de intocable- e hizo del propio retrato un género conflictivo pues se trataba de decir lo dicho pero de una manera todavía no dicha; esto es, se trataba de sobrepasar lo dicho a fuerza de repetirlo con nuevas galas del ingenio sustitutivo, o de convertirlo en una parodia más o menos fina, más o menos chusca.

Los dos retratos de Jacinto Polo que Sor Juana tuvo presentes al escribir sus ovillejos fueron el de Dafne - de la "Fábula burlesca de Apolo y Dafne" - y el de una mulata - del poema "Retrata un galán a una mulata, su dama" 5 . En el retrato de Dafne, el poeta se propone el ejercicio de recordar el canon paso a paso mientras lo subvierte de dos modos: por un lado trazando el retrato en un movimiento que avanza de los pies a la cabeza y, por otro, evitando recurrir a los símiles usuales, como hace el "principiante" o, dicho más enfáticamente, el "poeta de teta". El primer modo de

${ }^{5}$ Citaré ambas composiciones según la ed. de $B A E$. 
la subversión nace de una declaratoria de independencia poética, una baladronada cuya sola enunciación revela que estamos en los dominios de la sátira; que la declaratoria es a la vez una crítica y una confirmación de la efectiva dependencia: "Y pienso comenzar por los talones, / Aunque parezca mal al que leyere; / Que yo puedo empezar por do quisiere”. El segundo modo es todavía más interesante y productivo pues el poeta muestra su lucha contra los símiles y los consonantes y por ese camino vuelve del retrato al cuerpo. Por ejemplo cuando se trata de describir la boca, el poeta reflexiona: "(Vamos con tiento en esto de la boca; / Que hay notables peligros carmesíes, / Y podré tropezar en los rubíes, / Epítetos crüeles)"; y luego de rechazar también la tentación de comparar la boca con el clavel, su salida consiste en sugerir un retorno al origen, declarar la superioridad de lo real: "Es tan linda su boca, que no pide". Otro tanto ocurre con la descripción de las mejillas que, por ser encarnadas, prácticamente obligan a compararla con la rosa ("Jesús, Señor, ¡qué tentación de rosas! / Qué notable vocablo"); pero en este caso nuevamente el poeta evitará el peligro recurriendo al realismo: "Baste decir que están, por lo encarnadas / como de haberlas dado bofetadas; / Que éste es el arrebol que las colora". Paradójicamente, lo real no está aquí antes sino después de las palabras; es aquello a lo que se recurre para dejar atrás la proliferación de los vocablos y de las figuras. El cuerpo, pues, no aparece por la atracción que produce su presencia; esa presencia está convocada porque ha revelado su propiedad de ser más contundente que los gastados símiles, lo que quiere decir que aquí -como en el buen estilo gongorino- de lo que se trata es de sustituir las sustituciones.

Pero en esta lucha contra los símiles no siempre se alcanza la orilla del realismo. En el caso de la frente, el poeta finalmente concede que ésta tiene "sus ciertos humillos de azucena", lo cual produce de inmediato la siguiente reflexión, que le permite adentrarse más en el juego de decir lo dicho de manera no dicha: "Dije azucena; en fin, no pude menos; / Que el concepto me vino de apaleta; / Y así, ningún poeta, / Aunque sea el mejor de los mejores / Diga: «No beberé de aquestas flores»". De una o de otra manera, no deja de ser interesante el observar que por este camino, en el que se trata de llegar más lejos que las palabras, reaparecen formas de la percepción que la inspiración platónica había dejado en el olvido: la táctil (que hemos visto en la mención de las "bofetadas") y la olfativa (si el poeta rechaza la evocación de las rosas es porque "da cámaras sólo con olellas"; luego, al llegar a los cabellos, 
el poeta declara su repulsión por el "tufo" que de ellos provienen). Ambas formas de la percepción, como se puede observar, se presentan como un motivo antiestético.

Otro rasgo que tomó Sor Juana de esta "Fábula" es lo que podemos llamar la circunstancia enunciativa. Jacinto Polo comienza su poema poniendo en boca del poeta que tendrá la misión de recordar el conocido tema, la declaración siguiente: "Cantar de Apolo y Dafne los amores, / Sin más ni más, me vino al pensamiento. / Con licencia de ustedes, va de cuento". Este comienzo, pues, nos informa que el poeta no tiene otro motivo para evocar la fábula sino una súbita e inexplicada tentación, y sobre todo nos indica que se dirige a un auditorio. La circunstancia de dirigirse a un auditorio difuso pero próximo - "ustedes"- decidirá el carácter de la enunciación. El poeta buscará dejar demostrada su suficiencia como si tratara de salir triunfante de una prueba que él mismo ha provocado con el solo afán de autoconfirmarse ("Ahora falta lo mejor de todo: / Los ojos van ahora. / Yo seré un tal por cual si digo aurora; / Ténganme por un ruin si digo albas;") ante un público no por maravillado menos atento y dispuesto a sancionar cualquier caída: “¿Mas que temieron que dijera estrellas?”, desafiará, con triunfalismo evidente, para que sus complacidos jueces terminen de entender que un poeta de su categoría, conocedor del listado de símiles asociados a los ojos de las bellas, no tropezará con el más trivial después de haber evitado minuciosamente a los otros. Este motivo desarrollado por Polo de Medina no podía, creo, haber dejado de impresionar a Sor Juana, cuya obra nos la muestra continuamente en la actitud de poner a prueba su ingeniosa maestría ante un público -seguramente más real que imaginario- que ella misma creó y ante el cual no puede permitirse incompetencia alguna.

La "Fábula burlesca de Apolo y Dafne" está escrita siguiendo una libre combinación de heptasílabos y endecasílabos con rima pareada. Esta técnica, que también será utilizada por Polo de Medina en el poema "Retrata un galán a una mulata, su dama", es la que reproducirá Sor Juana en sus ovillejos. El retrato que Jacinto Polo hace de la mulata es más minucioso -y si se quiere más extravagante- que el de Dafne y acaso es el que causó más viva impresión en la monja mexicana no obstante haber tomado más motivos del retrato de Dafne ${ }^{6}$. Se trata en este caso de un retrato,

${ }^{6}$ Octavio Paz parece entender que Sor Juana tuvo presente sólo el poema "Retrata un galán a una mulata, su dama”, pero que no sólo se inspiró en Polo 
en su doble estatuto de composición visual y composición verbal; mejor dicho se trata de una composición verbal en la que las palabras realizan una doble función: pintar y significar. El poema, por lo tanto, sin transición nos lleva de una primera situación, ficticia en primer grado, en la que alguien está anunciando su actividad -verbovisual- de pintar un retrato mientras busca las palabras adecuadas para su propósito, a otra situación, ficticia en segundo grado, en la que alguien está, efectivamente, pintando el retrato. En el caso del poema de Sor Juana, ya lo veremos, debido a que la poeta-pintora se sitúa directamente frente a su público, la pintura se despliega inmediatamente ante sus - nuestros- ojos. En el caso del poema de Jacinto Polo la escena se nos muestra sesgada: el retratista - que es a su vez el amante- se dirige a su dama y es con ella con quien habla mientras ejecuta su pintura: ella es, pues, el modelo u original, el destinatario, y el espectador del retrato. Se trata aquí de un amante que en su afán de "Ablandar a su dama" se dispone a hacer su retrato "Con ingenio pintor y pincel pluma", sabiendo que, en estos casos, debido a la torpeza de la ejecución, “...cotejada la pintura / Con la viva hermosura / Le parece el retrato / Como a Zorobabel Poncio Pilato". Aunque la determinación de hacer el retrato tenga en el poema de Sor Juana otros motivos, ella repetirá, y amplificará, el tópico de la torpeza - y la obstinación-del retratista: "Yo tengo que pintar, dé donde diere, / salga como saliere, / aunque saque un retrato / tal que, después, le ponga: Aquéste es gato", declarará antes de emprender la pintura de Lisarda.

Este segundo retrato de Polo de Medina, que comienza "a lo usual por los cabellos", acumula dificultades, saltos y violencias puesto que la retratada, en su mulatez, es una negación de la belleza canónica, y el retratista, en su decisión de no ocultar las características reales de la dama, corrobora la negación: "Y si digo que son madejas de oro, / A mí y a su beldad pierdo el decoro, / Pues habrá quien me tache / De que vendo por oro el azabache, / Y fabricar mentiras semejantes / Más es de mercaderes que de

de Medina sino que sigue "más que a un modelo aislado, a una corriente" (Sor Juana Inés de la Cruz o Las trampas de la fe, F.C.E., México, 1982, p. 403). MÉndez Plancarte se inclina a pensar que siguió "sobre todo" la "Fábula burlesca de Apolo y Dafne" (véanse sus notas a los ovillejos: Obras completas, t. 1). Adolfo dE CASTRO (op. cit.) piensa que siguió únicamente y muy de cerca la "Fábula", pero tuvo también muy presente la otra composición ("Retrata...") y, si bien era consciente de que seguía una corriente paródica, su atención estaba fijada en esas dos composiciones de Jacinto Polo. 
amantes". ¿Cómo hacer el retrato de la dama y a su vez mantenerse en estos límites? El amante-pintor ensaya salidas conciliatorias. Ya que, al describir la frente, no puede decir que es "Leche, cielo, cristal y nieve ardiente" por las razones apuntadas, a medias entre la realidad y el canon, saldrá del paso con un: "Digo que es su color leche entintada / Ollín nevado y nieve azabachada”. Sin embargo, la continuación del retrato mostrará lo inconciliable de esa reunión. Los ojos, por ejemplo, tendrían que ser llamados estrellas rutilantes: "Mas ¿qué tienen que ver ojos y estrellas / Si ellos son negros, y doradas ellas? / Y cuando los llamara, / Del firmamento obscuro de tu cara / Luceros zahareños, / También para luceros son pequeños". La confrontación del "original" con lo que debería ser la "copia" es una continua desidealización, es decir un retorno continuo hacia la visión realista. ¿Quiere decir que en esta parodia la presencia del cuerpo se ha impuesto a su imagen retratada y, por lo tanto, que la realidad ha quedado confirmada en detrimento del arte? Como he tratado de mostrarlo en otras oportunidades ${ }^{7}$, el arte manierista se mueve sobre un borde que reúne, muchas veces vertiginosamente, un irrenunciable realismo con una rigurosa sujeción a los mandatos del arte entendido éste como obsesivo artificio. La chusca negación del canon de la belleza femenina que parece ser el tema de esta parodia, negación que brota de un fuerte sentimiento realista, en realidad no hace sino confirmarlo.

El breve análisis de los retratos de Dafne y de la mulata acaso ha sido suficiente para mostrar que allí no se ridiculiza o niega validez al canon de belleza femenina sino a los poetas que, faltos de ingenio, repiten servilmente los símiles usuales o, faltos de verdad, atribuyen al cuerpo retratado cualidades que está lejos de tener. Para ser bella es necesario ser rubia, blanca, tener los ojos brillantes y las mejillas encarnadas. Eso está por completo fuera de la discusión. Una mulata no puede ser bella y todo intento de hacerla pasar por tal supone la astucia de cambiar "oro" por "azabache". El realismo de la parodia consiste en poner de manifiesto dos verdades: 1) no hay cuerpo que satisfaga por completo el ideal de la belleza y la relación "original-copia" está alterada: el original no es el cuerpo vivo sino el ideal prescrito por el canon; si el retrato es una copia del original -es decir, del ideal canónico-, su ejecución supone poner entre paréntesis el cuerpo vivo, volverlo

\footnotetext{
${ }^{7}$ Véanse Los extremos del lenguaje..., y "En torno al Polifemo y a las Soledades de Góngora”, Hablar de literatura, F.C.E., México, 1989.
} 
transparente para ver a su través el ideal canónico; 2) lo que interesa en el retrato no es el cuerpo sino el juego de los símiles; lo que se ofrece a la admiración de los lectores no es la hermosura de una mujer sino el ingenioso trabajo de un poeta.

De ahí que la parodia del retrato sea una confrontación de ingenios. Lo que el parodiador ofrece no es otro cuerpo sino otra manera de jugar con los símiles pues la parodia es un tejido de figuras tanto o más elaboradas -y que se pretenden más ingeniosas- que las composiciones del género parodiado. Tales símiles son tan hiperbólicos como los del género parodiado y se mueven sobre una misma línea aunque tienen una función contraria. Mientras en el retrato la función es meliorativa, en su parodia es peyorativa: si, en el retrato, los cabellos de la hermosa son rayos de sol, en la parodia los cabellos de la mulata serán "morcillas". En última instancia, la impresión de realismo que produce la parodia está dada por el valor peyorativo -o, si se quiere, el disvalor- de las figuras, por su carácter antipoético, por el buscado prosaísmo que produce la ilusión de sustraernos del arte y devolvernos a la vida. De un modo o de otro, tanto en el retrato "serio" como en el paródico, el cuerpo vivo está fuera de la escena, en un espacio en que resulta intocable y también indecible.

"No hay que olvidar que la amada podía ser rubia o morena, de abundante o escasa cabellera, esbelta o no, siempre se le cantaba igual", advierte Martha Lilia Tenorio en un ensayo dedicado al retrato en Sor Juana ${ }^{8}$. Resulta doblemente interesante citar este artículo porque en él su autora, acertadamente en mi opinión, reduce a ocho las composiciones poéticas de Sor Juana en las que podemos hablar estrictamente de elaboración de retratos y con ello corrige a Georgina Sabat ${ }^{9}$, quien había llevado a dieciséis el número de estas composiciones, y porque, aunque sin citarlo, ayuda a despejar ciertas ambigüedades y hasta alguna contradicción en el estudio que Sylvia Graciela Carullo dedica a este tópico en la poesía de Sor Juana. En efecto, en el capítulo 2 de El retrato literario en Sor Juana Inés de la Cruz ${ }^{10}$, Carullo pasa revista al tema de la elaboración del retrato desde la Antigüedad clásica hasta el siglo XVII para mostrar "cómo el retrato evoluciona de una representa-

8 "Copia divina: la tradición del retrato femenino en la lírica de Sor Juana", LMM, 5 (1994), p. 18.

${ }^{9}$ Véase "Sor Juana: la tradición clásica del retrato poético", en De la crónica a la narrativa mexicana, eds. M. H. Forster y J. Ortega, Oasis, México, 1986, pp. 79-93.

10 P. Lang, New York, 1991. 
ción genérica a una caracterización física particularizada y, luego, psicológica del individuo" (p. 35), cosa que ocurre, según ella, sobre todo en el Renacimiento a partir de las reflexiones y de la obra de Leonardo da Vinci. Sin embargo, páginas más adelante, observa que "es bien sabido que los principios estéticos renacentistas concebían una belleza ideal que se distinguía por determinadas preferencias: cabellos rubios, ojos claros, miembros blancos y armoniosos" (p. 44). Esta contradicción, que creo más aparente que real, acaso se deba a que la autora por un lado toma en cuenta el contexto general de la elaboración de retratos artísticos -especialmente en la obra de los pintores-y por otro la tradición específica del retrato femenino en la poesía, y no establece las precisiones suficientes para distinguir esta última. Por su parte, Martha Lilia Tenorio, más centrada en su objeto, y apoyada en un estudio de Edmond Faral, afirma sin vacilar: "sin pretensión de objetividad o de realismo, el retrato se concebía esencialmente como un ejercicio poético"11.

Lo que se dice, pues, no es el cuerpo. Lo que se dice es un decir preestablecido; lo que se elabora es un poema. Y si eso ocurre en el retrato, otro tanto, o quizá un tanto mayor, ocurre en la parodia. La parodia depende enteramente de lo parodiado, y no puede entenderse sin un retorno a su fuente. El retrato, si bien no es creíble visto como "copia" de un cuerpo real, tiene su propia verosimilitud. Ningún cabello es más brillante que el sol, ninguna piel es más blanca que la nieve y nunca nadie pretendió que esas hipérboles fueran tomadas literalmente, pero tal exaltado elenco de atributos traza una imagen verosímil en el que las piezas se relacionan unas con otras según una misma isotopía. En la parodia, en cambio, cada pieza no busca adecuarse a la anterior o a la que le sigue sino a aquélla a la que ridiculiza. El cuerpo que sugiere no tiene verosimilitud porque las líneas isótopas no recorren esa imagen del cuerpo sino que van y vienen del modelo a la réplica. El cuerpo que sugiere la parodia, más que un cuerpo intocable, es un cuerpo desintegrado, hecho de piezas sueltas cuyo valor consiste en ser la sombra, o el hueco, de una pieza que tiene el valor contrario y que pertenece a otra imagen.

En el ensayo de Martha Lilia Tenorio, la autora sostiene que en la obra poética de Sor Juana podemos contar hasta ocho com-

${ }^{11}$ M. L. Tenorio, art. cit., p. 6. El Libro de Edmond Faral es -según la referencia bibliográfica de la autora-Les arts poétiques du xii et du xiii siècle, Libraire Ancienne Honoré Champion, Paris, 1924. 
posiciones que constituyen propiamente retratos ${ }^{12} \mathrm{y}$ que esas ocho composiciones pueden ser reunidas en dos grupos: uno integrado por retratos de intención "cortesana" - caracterizados por su "complicada elaboración formal"- y otro "constituido por dos poemas notables": uno notable por su "belleza" (el romance decasílabo dedicado a la Condesa de Paredes) y el otro por "el ingenio e inteligencia con los que Sor Juana trabaja el código de la descripción femenina" (p. 11). Por mi parte, no estoy totalmente convencido de que entre el tan comentado romance decasílabo ("Lámina sirva el Cielo al retrato") y los otros de intención cortesana haya una diferencia profunda, pero eso es tema para otro análisis ${ }^{13}$. Lo que sí me parece pertinente, es el dedicarle a los ovillejos en que Sor Juana hace el retrato de Lisarda una atención especial.

$\mathrm{Al}$ hacer el retrato de Lisarda -como es habitual en el temperamento de nuestra poeta-, más que imitar, Sor Juana buscará sobrepasar; en todo caso, dejar demostrado que ella puede tanto como los más célebres ingenios de su tiempo, y que tal vez se eleva un poco por encima de ellos. Así el poema en que "Pinta en jocoso numen, igual con el tan célebre de Jacinto Polo, una belleza”, mucho más que un retrato es un despliegue de motivos y temáticas que componen una especie de arte poética en negativo: a través de chanzas, de esguinces, de veladas críticas, Sor Juana expone en ese poema una reflexión sobre la poesía de su tiempo y sobre su propia manera de tratar la materia poética, sobre las dificultades y astucias del oficio, sobre las formas de valoración y

12 Tales composiciones serían las que en la ed. de Méndez Plancarte llevan los números 41, 43, 61, 71, 80, 87, 132 y 214. Llama la atención que de estos ocho retratos, tres estén dedicados a la Condesa de Galve (el 41, el 43 y el 80) y sólo uno a la Condesa de Paredes (el 61). Por alguna razón que, sospecho, tiene más que ver con las indagaciones sobre la vida de Sor Juana $-\mathrm{y}$ de lo que a partir de ellas puede conjeturarse- que con la lectura de estas composiciones, se ha hecho frecuente asegurar que el retrato dedicado a la Condesa de Paredes está dotado de una carga erótica especial, mientras los otros - por ejemplo, los dedicados a la Condesa de Galve-son ejercicios retóricos o requiebros cortesanos. Según lo que yo alcanzo a leer, de estos ocho retratos, hay tres (el 41, el 61 y el 214) que se caracterizan por apegarse con mayor "ortodoxia" al desarrollo del modelo canónico, salvo que los dos primeros (dedicados, respectivamente, a la Condesa de Galve y a la de Paredes) lo siguen en positivo y el tercero, el de Lisarda, en negativo, es decir mediante un juego paródico. Creo que esos tres son en el fondo el mismo retrato.

${ }^{13}$ Del análisis, y de una posible interpretación, de ese romance decasílabo me ocupo en el artículo "El deseo y la vislumbre", en Los cuadernos de Sor Juana, ed. M. Peña, UNAM, México, 1996, pp. 307-327. 
sobre la función del poeta. Desde luego, los comentarios y críticas desplegados por nuestra poeta no pueden ser tomados en su literalidad -esto es, como una declaración de independencia estética- porque ella no se aparta de las formas establecidas y no se aparta tampoco de su persistente afán por ponerse a prueba mostrando ante los demás su aptitud para acometer con maestría todas las formas poéticas en boga. Sin embargo, debemos también reconocer que, sobre todo en la poesía manierista, la parodia es una manera de dar salida a la inconformidad que las leyes de un determinado género, o de todo el estilo, a la larga producen, una autocrítica regulada pero no por ello inocua, y que haber elegido esa forma de expresión no es finalmente un puro juego. De una o de otra manera, en estos ovillejos Sor Juana se muestra y muestra a su vez el horizonte y las expectativas de su quehacer.

Más bien extenso, este poema está encuadrado en una situación enunciativa perfectamente acotada: la artista se dirige a un público -ciertamente convocado por ella misma- ante el cual se someterá a la prueba de "pintar" un retrato. Se trata a la vez de pasar un examen y de brindar un espectáculo. El espectáculo consiste en una representación verbal-visual y el espectador, por ello, debe asumir que la pluma es a la vez un pincel y que las palabras tienen el valor del trazo. También de entrada se define el estilo en que la artista se comunicará con su público: se trata del "estilo llano", es decir el usual en aquellos géneros en que -como la parodia- la agudeza se da a conocer por maneras aparentemente familiares e incluso vulgares, aunque la apelación a la vulgaridad sea un tópico y en última instancia una especie de coquetería de personas cultas. Así, pues, los cuatro primeros versos definirán el tema, el tipo y la forma de la ficción poética: "El pintar de Lisarda la belleza / en que a sí se excedió Naturaleza, / en un estilo llano, / se me viene a la pluma y a la mano". Pero la artista no acometerá de inmediato la pintura de Lisarda sino que antes exhibirá los obstáculos que para ello debe vencer; esos obstáculos provienen de dos fuentes: $a$ ) la propia ineptitud, y $b$ ) el estado actual del género. Se trata, entonces, de anteponer al retrato una disertación, una actividad puramente verbal que ponga al público en conocimiento de la situación y, sobre todo, que lo incline a su favor. Toda la composición está tratada como una sola pieza retórica, con su exordio, su exposición de motivos, su desarrollo y su desenlace. Este tratamiento es el que permite decir cosas nuevas sin salirse de lo establecido, esto es, repetir lo dicho en forma no dicha. 
En el capítulo 5 de su importante obra Literatura europea y Edad Media latina-dedicado al estudio de la "Tópica en la antigua Retórica"-, Ernst Robert Curtius cita el motivo de "la falsa modestia" como un recurso al que solían apelar los oradores. "En la introducción -dice Curtius-, el orador debe ganarse la benevolencia, la atención y la docilidad de sus oyentes. ¿Cómo lograrlo? Ante todo, con una presentación modesta" 14 . Este motivo pasa de la oratoria forense -donde el abogado tiene que inclinar a su favor el ánimo del juez- a los demás géneros y se perpetúa a lo largo del tiempo con el agregado de una gran variedad de "fórmulas de modestia". De estas fórmulas una es la ignorancia, la torpeza o debilidad del propio talento, fórmula recurrente en Sor Juana y usada una vez más en estos ovillejos: "Y cierto que es locura / el querer retratar yo su hermosura, / sin haber en mi vida dibujado, / ni saber qué es azul o colorado". Siguiendo en este caso a Jacinto Polo en su fábula -cuya evocación, declara la autora, le vino al pensamiento "sin más ni más"-Sor Juana no recurre aquí a otra de las fórmulas que tiene al alcance de la mano: la de la obediencia a un mandato. Según Curtius, sobre todo en la Edad Media, se difundió -dentro de la tópica de "la falsa modestia"- el antiguo recurso de afirmar que "el autor sólo se atreve a coger la pluma porque un amigo, protector o superior se lo ha sugerido, pedido o mandado" (p. 130). Sin duda, dado que en este caso, por tratarse de una composición en "estilo llano", la fórmula del mandato se hace menos "verosímil", Sor Juana pudo seguir con comodidad el ejemplo de Jacinto Polo. No sería hablar bien de una persona, en efecto, atribuirle la petición o la sugerencia de que ella escribiera una composición chusca. En ese sentido, atribuir el retrato a un impulso de su propio deseo es hasta cierto punto un gesto de modestia, aunque sabemos que el motivo del mandato será invocado por Sor Juana -con un grado de veracidad que no podemos conocer- cuando haga la defensa de su trabajo poético ante los terribles jueces que tuvo que enfrentar.

El justificar que, a pesar de su torpeza, se decida a acometer el retrato de Lisarda, le dará a Sor Juana ocasión de deslizarse sutilmente hacia la crítica de tanto retratista aficionado que hizo el mismo intento con resultados mediocres: "Pues no soy la primera / que, con hurtos de sol y primavera, / echa con mil primores / una mujer en infusión de flores: / y... / cuando el hervor se entibia, / pensaban que es rosada y es endibia”. Más interesante to-

14 Trads. M. Frenk y A. Alatorre, F.C.E., México, 1995, t. 1, p. 127. 
davía resulta la presentación del segundo obstáculo para la elaboración del retrato, esto es, el estado actual del género. Entre chanzas, este tema alude a las dificultades que debieron vencer los poetas del siglo XVII para producir la siempre necesaria impresión de novedad: " $\mathrm{O}$ Oh siglo desdichado y desvalido / en que todo lo hallamos ya servido, / pues no hay voz, equívoco ni frase / que por común no pase / y digan los censores: / ¿Eso? ¡Ya lo pensaron los mayores!". Tal lamento es la explicación del manierismo: esa tensión entre el repetir y el variar, el sentirse preso de una retórica y a la vez acometerla con tal decisión que, bordando sobre lo bordado, la propia retórica sirva como trampolín para la elaboración de figuras cada vez más audaces. Con curiosa rebeldía, el manierismo protesta contra un modelo impuesto reproduciéndolo con tal obsesión que lo lleva al punto de destruirlo o, al menos, de vaciarlo de sentido. Siguiendo a otros poetas, y apelando al buen humor de las musas, Sor Juana se lamenta de que ya no quede símil novedoso del que echar mano y - poniendo, en un pase de malabarista, el referente en el lugar de la palabra- de que los elementos naturales a los que los poetas acudieron tantas veces han perdido su brillo o su frescura; las estrellas, el sol, las perlas, la grana ruedan ahora entre los versos, fatigados, sin el esplendor de otros tiempos: “iDichosos los antiguos que tuvieron / paño de que cortar, y así vistieron / sus conceptos, / de luces, de reflejos y de flores!"

Una lectura ingenua, literal, de esta exposición de penurias podría terminar en una pregunta como la siguiente: ¿por qué, si los poetas estaban cansados de utilizar las mismas metáforas, no construían otras? En el poema Ella, Vicente Huidobro escribió: "Ella tenía ojos de adormecedora de mares", y Aleixandre, otro Vicente, en su poema Ven, siempre ven, describió los ojos de la amada como "dos imperiosas llamadas de una hondura que no conozco". ¿Por qué los poetas manieristas no hicieron algo semejante? Esta pregunta conduce a la reflexión, ya menos ingenua, de que para ellos el universo de la poesía, como el mundo, como las formas de relación, como la moral, tenía límites precisos. Así, la imagen de la belleza femenina estaba constituida por un repertorio finito de atributos y de símiles aplicables a tales atributos. Esta convicción, y la otra que se deriva de ella, a saber, que ese enlace entre el atributo y el símil habían alcanzado ya su plenitud en una edad dichosa, denuncia, o acaso confirma, que este universo proviene de la cultura pagana para la cual la perfección se sitúa en el pasado, y uno podría sorprenderse de que haya sido 
defendida por tanto clérigo y por la misma Iglesia, tan profundamente permeada por los principios clásicos ${ }^{15}$. Pero éste es otro tema. Lo que me interesa observar en el presente ensayo es que, agotado el repertorio de relaciones atributo-símil, los poetas ansiosos de novedad ya no podían avanzar en el terreno semántico salvo cambiando la tonalidad, volviéndose sobre este terreno por vía de la caricatura o la parodia. En cuanto a la poesía "seria", sólo le quedaba explotar la sintaxis, buscar no nuevos símiles sino nuevas formas del enlace, construir metáforas de segundo o tercer grado. El retrato de la ninfa Galatea ejecutado por Góngora en la Fábula de Polifemo y Galatea es quizá el ejemplo más acabado del vértigo de combinaciones en que puede convertirse la descripción de una mujer (convencionalmente) hermosa ${ }^{16}$. Tanto la parodia como las metáforas construidas sobre metáforas suponen un progresivo alejamiento de lo real, o del sentimiento de lo real, un reemplazo de este sentimiento por el afán de construir una maquinaria lingüística.

Jorge Luis Borges, en un breve artículo dedicado a la metáfo$\mathrm{ra}^{17}$, recordó que Aristóteles, en su Retórica, había observado que la metáfora surge de la intuición de una analogía entre cosas disímiles, es decir, que la metáfora está fundada sobre una aproximación a $-\mathrm{y}$ de- las cosas, y no sobre el ingenio verbal. Al mismo tiempo, evocó la compilación que Snorri Sturluson - un historia-

${ }^{15}$ Indudablemente, se trata de una reflexión elemental. La composición de la cultura en la Nueva España, pero también en España, con todos sus matices, ha sido descrita en forma exhaustiva por Octavio PAZ (op. cit.).

${ }^{16} \mathrm{El}$ retrato, que habla de los sentimientos de Polifemo, es éste: "Ninfa de Doris hija, la más bella, adora, / que vio el reino de la espuma. / Galatea es su nombre, y dulce en ella / el terno Venus de sus Gracias suma. / Son una y otra luminosa estrella / lucientes ojos de su blanca pluma: / si roca de cristal no es, de Neptuno, / pavón de Venus es, cisne de Juno". La versión que Dámaso Alonso (Poesía española, pp. 371-376) hace de esta octava es la siguiente: adora Polifemo a una ninfa, hija de Doris, y la más bella que ha visto el reino marino de la espuma. Se llama Galatea y en ella resume dulcemente Venus los encantos de sus tres Gracias. Son sus ojos dos luminosas estrellas: lucientes ojos que fulguran sobre su piel tan blanca como la pluma del cisne. Reúne, pues, Galatea, las características combinadas del pavón o pavo real (tener ojos en la pluma) y del cisne (tener la pluma blanca). Y como el pavón está consagrado a Juno y el cisne a Venus, podemos decir que es un pavón de Venus (pavón, por los ojos; de Venus por ser blanca como el cisne de Venus), o bien, cisne de Juno (cisne por la blancura; de Juno por los ojos "de su pluma": cualidad del pavón de Juno); si ya no queremos llamarla roca o escollo cristalino de los mares de Neptuno.

17 "La metáfora", en Historia de la eternidad, Prosa, Círculo de Lectores, Barcelona, 1975. 
dor y poeta islandés del siglo xIII- hizo de las métaforas tradicionales de la poesía islandesa, donde, por ejemplo, las fórmulas "halcón de la sangre", "cisne sangriento" o "cisne rojo" servían para nombrar al cuervo, y razonó: "los tropos conservados por Snorri son (o parecen) resultados de un proceso mental que no percibe analogías sino que combina palabras; alguno puede impresionar (cisne rojo, halcón de la sangre), pero nada revelan o comunican" (p. 213). Estas menciones y este comentario, acaso excesivo, nos conduce a otro ensayo de Borges en el que estudia con más detenimiento tales perífrasis convencionales acumuladas por la poesía tradicional islandesa, puntuales aparatos retóricos llamados kenningar cuyo mecanismo permitía multiplicar las ingeniosas $-\mathrm{o}$ simplemente laboriosas- designaciones sobre todo de los elementos que formaban parte de la vida cotidiana de esa lejana cultura cuyo horizonte era el mar y cuya forma de vida era la guerra: el barco, la espada, la batalla, la sangre, etc. El estudio de este mecanismo ha sido recientemente expuesto por Margrét Jónsdóttir ${ }^{18}$ en un artículo en el que precisamente se dedica a comentar la relación que a lo largo de su vida mantuvo el escritor argentino con la literatura islandesa medieval. De acuerdo con Jónsdóttir, en su presentación más simple, o sea en su ejecución primaria, una kenning, es una fórmula "compuesta por dos sustantivos, uno de los cuales va en nominativo (la palabra de base), y el otro va generalmente en genitivo" (p. 128). Así por ejemplo, el aire puede ser designado como "morada del pájaro", perífrasis binaria en la que "morada" es "la palabra de base y 'del pájaro' es la palabra que define la anterior". Esta fórmula -aquí de primer grado- permite la superposición de nuevas fórmulas que, usando idéntico mecanismo, pueden a su vez sustituir a uno o a los dos términos. Así, la kenning "yelmo del aire", utilizada para designar el cielo, se convierte en "yelmo de la morada del pájaro". Tal procedimiento permite multiplicar los estratos de la metáfora. El mismo Borges cita este vertiginoso artefacto verbal: los aborrecedores de la nieve del puesto del halcón; literalmente incomprensible, dicha metáfora puede descomponerse, según lo explica Borges, de la siguiente manera: el "puesto del halcón es la mano; la nieve de la mano es la plata; los aborrecedores de la plata son los varones que la alejan de sí, los reyes dadivosos" 19 . Borges -a quien, de cualquier modo, le resulta

18 "Borges y la literatura islandesa medieval", AP, 16 (1995), 123-157.

${ }^{19}$ Jorge Luis Borges, "Las kenningar", en Historia de la eternidad, p. 206. Por lo que se ve, la poesía tradicional islandesa parece haber insistido en una única 
inevitable el sentir una cierta fascinación ante tales malabarismos lingüísticos- no deja tampoco de prodigar su desprecio por estas "frías aberraciones" que hacen de la poesía un juego de la inteligencia analítica, y no deja de asociar estos juegos con el de los poetas manieristas $-\mathrm{y}$ aun de los simbolistas- a quienes extiende su inestable sentimiento de admiración y de desprecio. "El culteranismo -dice- es un frenesí de la mente académica" (p. 207). También Hauser, en su estudio del manierismo, después de reflexionar que el "verdadero arte es, si no una «corrección", al menos una interpretación del sentido de la vida", se preguntaba: “¿Y qué es lo que la metáfora puede aportar en esta tarea?” (op. cit., t. 3, p. 61). De todos modos si cito estos ejemplos no es para adherirme a los juicios negativos -estos juegos son, por lo menos, una excelente manera de adentrarse en los secretos de una lengua- sino para observar que ellos también derivan de un trabajo que explota los recursos sintácticos y en ese sentido -aunque el tipo de procedimiento no sea específicamente el mismo- se trata de un notable antecedente que permite entender la ilustrativa exposición que hace Sor Juana de la poesía de su tiempo. No nos consta que los poetas islandeses hayan desarrollado a la vez una conciencia crítica de su propio trabajo; más bien, por lo que conocemos, nos queda la impresión que se entregaron a él con verdadero - ¿e ingenuo? - entusiasmo. A este respecto la poesía del siglo XVII

técnica que resulta de la misma ecuación sintáctica (aunque Borges refiere que también las kenningar incluían las aliteraciones como efecto importante). La poesía manierista ha desarrollado una gran variedad de recursos ingeniosos, aunque todos se caracterizan por tratarse de procesos verbales que pueden ser reconstituidos racionalmente. Entre esos recursos está el usado por los poetas islandeses. Los ejemplos abundan: Góngora llamó "reino de la espuma" al mar, "cítaras de plumas" a los pájaros, y "campo de zafiro" al cielo de la noche; mientras Quevedo, en un solo soneto, llamó a la rosa "mocedad del año", "ambiciosa vergüenza del jardín", "del año presunción hermosa", "deidad del campo" y "estrella del cercado". Por su parte, Sor Juana llamó "imán del viento" al pulmón, "templada hoguera del calor humano" al estómago, o "pámpanos de cristal" a los brazos de la Condesa de Paredes. En nuestro siglo, siguiendo la huella de estos poetas, Miguel Hernández designó, con un gusto en verdad poco definible, el pie de la amada con esta perífrasis: "perro sembrado de jazmín calzable", perífrasis cuya base es: "perro de jazmín". Pero volviendo al siglo xvII, no podemos dejar de notar que el propio Jacinto Polo, en su "Retrato del autor", después de usar un tono inmisericorde para describir sus miserias físicas (como había descrito otras ajenas) vuelve al tono jactancioso para elaborar una burla del estilo culterano componiendo dos figuras que, por su tema, son una perfecta réplica de las que varios siglos antes gustaban de ensayar los bardos de las cortes islandesas: "Llamo al mar cielo de peces, / Peine del viento a la nave". 
presentaría el interés de ser una poesía que no sólo se entregó a ese "frenesí de la mente académica" al que alude Borges, sino que a la vez lo hizo con verdadera lucidez crítica -lucidez no exenta de pesimismo-, como lo muestran los ovillejos compuestos por Sor Juana.

Llevada a cabo con humor paródico, la disposición crítica expuesta por Sor Juana es una necesidad en el desarrollo de su propia poesía y una forma de la astucia que le permite deslizar otras críticas hechas en su defensa. Después de haber reunido queja y chanza, después de haber observado que "así andan los poetas desvalidos / achicando antiguallas de vestido ...y pensando que pintan de los cielos / hacen unos retablos de sus duelos", la monja puede aprovechar la ocasión para, fingiendo que retorna al tópico de la falsa modestia, dirigir una maliciosa alusión a los que se dedican a censurar: "Pero diránme ahora / que quién a mí me mete a ser censora, / que, de lo que no entiendo, es grave exceso; / pero yo les respondo que por eso: / que siempre el que censura y contradice / es quien menos entiende lo que dice". Imposible no leer en estos versos una velada censura a sus censores los cuales, como sabemos, fueron muchos y fueron poderosos.

Después de este examen de la situación, todavía la artista alejará el momento de ponerse a la tarea de ejecutar el retrato para exponer sus dificultades personales y hacer su propio descargo. Este segmento del poema es particularmente interesante porque Sor Juana muestra cuáles son sus preocupaciones más comunes al ejecutar un poema: la selección de los vocablos adecuados al estilo, la búsqueda del consonante (o del asonante en otras composiciones) y, desde luego, la elección del símil, motivo este último en el que se explayará cuando se entregue a la elaboración del retrato. Esta composición está en estilo llano pero aun dentro de este estilo cabe escoger, preferir y desechar: "Digo, pues... ¡Oh qué pueses tan soeces! / Todo el papel he de llenar de pueses". Este primer tropiezo es el inmediato motivo de un segundo: "iJesús, qué mal empiezo! / Pincipio iba a decir, ya lo confieso, / y acordéme al instante / que principio no tiene consonante". Pasajes como éste justifican, espero, mi observación de que este poema puede leerse como un arte poética, pero un arte poética en negativo, donde la definición del trabajo artístico, las reflexiones que suscita y los propósitos que con él se persiguen están representados no por los logros que el autor se adjudica sino por los defectos que trata de evitar; definición, reflexiones y propósitos, pues, a los que no llega por la vía de la afirmación sino por la de la negación de la negación. 
Luego de esta larga exposición de motivos y de este minucioso examen de la situación, el retrato, como es de suponerse, resulta una aplicación que corrobora lo dicho. Más que un retrato, es una burlesca denuncia del modo de hacer retratos. Como en el caso de la pintura de la "mulata" de Jacinto Polo, el retrato sigue el orden canónico; pero como en el caso de la pintura de Dafne, el tema no es tanto la descripción de un cuerpo sino el repertorio de símiles que se usa en estos casos. El juego consiste en ir nombrando esos símiles y al mismo tiempo evitarlos, es decir, en nombrarlos para mostrar que aquí se los evita. Habiéndose anunciado como una "pintura", el comienzo del retrato nos encuentra dispuestos para enfrentarnos a una imagen distanciada, reducida a las impresiones visuales y por lo tanto inaccesible para las otras formas de la percepción. Pero de inmediato este retrato se transforma en un laborioso análisis de la comparación, esto es, del término sustitutivo: "Por el cabello empiezo, esténse, quedos, / que aquí hay para pintar muchos enredos; / no hallo comparación que bien le cuadre". He subrayado los vocablos "pintar" y "comparación" para mostrar cómo el primero se absorbe en el segundo. La expresión "pintar muchos enredos" es desde luego una alusión a lo enredado de los cabellos de Lisarda - no se olvide que se trata de una parodia- pero el "enredo" es en realidad la maraña de símiles a que el cabello ha dado lugar - "Rayos de Sol", "Cuerda de arco de Amor", etc.- y sobre todo el difícil trance de pasar a través de esa maraña sin enredarse: "En ser cabello de Lisarda quede / que es lo que encarecerse más se puede”. Este recurso al realismo es uno de los desenlaces del enredo, del problema propuesto por el afán de repasar el repertorio de símiles y no utilizar ninguno de ellos. Si, por ejemplo, las cejas son "arcos", no serán arcos "de Cupido" ni tampoco el arco-iris ("la paz del día") sino arcos de una "cañería" o acueducto, es decir de un vertedero de lágrimas. En cuanto a las mejillas (que podría rimar con "maravillas" o que pueden estar afeitadas de "carmín y grana") finalmente "son carne y no otra cosa". Por su parte, la mano (primero la derecha y después la izquierda porque "es la una mano como la otra mano") resulta ser "blanca y hermosa con exceso, / porque es de carne y hueso" y resulta estimable "no porque luce, porque agarra”.

El recurso al realismo es una de las formas de rematar el proceso de evasión del símil. La otra - quizá todavía más "subversiva"es declarar que la comparación no es, después de todo, obligatoria. Los ojos de Lisarda dan lugar al proceso más largo y al más per- 
sistente fracaso en la búsqueda del "símil competente", fracaso que se resuelve en una especie de rebeldía ante las constricciones de la preceptiva ("Que no todo ha de ser comparaciones") y, finalmente, en una declaración de que los símiles pueden tener un efecto, en vez de enaltecedor, degradante: "pues a sus niñas fuera hacer ultraje / querer tenerlas siempre en pupilaje". Pero finalmente esta declaración es, como se ve, el motivo de otra ingeniosidad, de una figura que juega con el doble sentido del vocablo "niña": mujer de corta edad, y pupila de los ojos.

La supuesta fuga de los laberintos verbales no crea sino nuevos laberintos, más alejados aun del cuerpo vivo. En este retrato hay todo menos un cuerpo. El recurso al realismo, el decir que las mejillas "son carne y no otra cosa", no nos acerca a una determinada imagen de mujer sino a una recusación del símil. Se trata de una expresión que, lejos de traernos de regreso de los juegos del ingenio, nos adentra más en la maquinaria verbal que ha dado origen a los procedimientos sustitutivos: no se trata de un movimiento en círculo sino en espiral, un movimiento en ese sentido semejante al que traza Góngora cuando - en la Soledad Segundael pescador Micón se refiere al agua como "luciente cristal" (lo cual es de práctica) pero enseguida agrega que el cristal es "agua al fin dulcemente dura": la mención del agua, pues, no conduce de retorno al primer término -el que designaría lo real-sino que aparece ahí para sustituir al que lo ha sustituido, como un símil de segundo grado. Estamos, pues, siempre ante la búsqueda del deslumbramiento, del hallazgo verbal. Octavio Paz celebró la "gracia" - la rápida levedad- con que Sor Juana describe la cintura de Lisarda: "porque ella es tan delgada / que en una línea queda ya pintada". Airoso, este hallazgo nos indica que la cintura existe como motivo del verso, del mismo modo que cuando -recurriendo, en este caso, a un ya gastado juego de palabras- explota la bisemia del sustantivo pie: "pero según airoso el cuerpo mueve / debe ser el pie breve, / pues que es, nadie ha ignorado, / el pie de Arte Mayor, largo y cansado".

Con lo que llevamos dicho podemos concluir -aunque sea por vía de hipótesis- que el retrato femenino en la poesía manierista es una composición ritual que celebra la ausencia del cuerpo. Es esta ausencia - el hecho de relegar el cuerpo al espacio de lo intocable e indecible- lo que permite precisamente que el retrato despliegue sus posibilidades sin interferencias, que se realice en plenitud. El cuerpo no es el original sino el obstáculo, un obstáculo que, para bien o para mal, los poetas salvaron o ignoraron sin 
remordimientos. Los ovillejos de Sor Juana son en última instancia un análisis de las causas de esta ausencia y también un análisis de las vías habitualmente utilizadas para remontar el obstáculo. De ahí, me parece, su singular importancia. Los poetas manieristas son los que probablemente - entre todos- tuvieron la conciencia más clara del arte de componer versos pero nunca hablaron de ello salvo en los propios versos y, en tal sentido, la parodia es el género que les permitía hacer de su propio trabajo un objeto de reflexión. La parodia - en este caso la parodia del retrato- es la muestra de la "fábrica" del género.

RAÚl DorRa

Universidad Autónoma de Puebla 